\title{
A Spider in a Broken Web: Nurses' Views on Discharge Planning for Older Patients after Hip Fracture Surgery Who Live in their Own Homes in Rural Areas
}

\author{
Cecilia Segevall, Kerstin Björkman Randström, Siv Söderberg \\ Department of Nursing Sciences, Mid Sweden University, Östersund, Sweden \\ Email: cecilia.segevall@miun.se, kerstin.bjorkman-randstrom@miun.se,siv.soderberg@miun.se
}

How to cite this paper: Segevall, C., Randström, K.B. and Söderberg, S. (2018) A Spider in a Broken Web: Nurses' Views on Discharge Planning for Older Patients after Hip Fracture Surgery Who Live in their Own Homes in Rural Areas. Open Journal of Nursing, 8, 405-418. https://doi.org/10.4236/ojn.2018.87032

Received: June 5, 2018

Accepted: July 6, 2018

Published: July 9, 2018

Copyright $\odot 2018$ by authors and Scientific Research Publishing Inc. This work is licensed under the Creative Commons Attribution International License (CC BY 4.0).

http://creativecommons.org/licenses/by/4.0/

(c) (i) Open Access

\begin{abstract}
Introduction: The in-hospital rehabilitation of patients who have undergone surgery for hip fracture requires a team-based effort, in which nurses play an all-embracing role throughout the patients' hospital stays. Although discharge planning has been widely studied, little is known about discharge planning from hospitals to homes in rural settings. Aim: To describe nurses' views on discharge planning for older patients after hip fracture surgery who live in their own homes in rural areas. Methods: A qualitative method was used. Four focus group interviews were conducted with 18 nurses who work at an orthopaedic clinic. The interview texts were analysed with qualitative content analysis. Findings: Nurses expressed that patients needed support from healthcare personnel as well as relatives in order to prepare for life at home. They also expressed that patients were not supported in all aspects of discharge planning because they faced difficulties in having their voices heard. Nurses described that many of those aspects were beyond their own control, which had left them with little to non-ability to influence discharge planning. Findings additionally indicate that discharge planning seems not affected by occurring in rural settings. Conclusions: Although discharge planning is intended to meet the unique wishes and needs of each patient given the realities of existing resources, nurses' responsibilities in discharge planning are unclear. This study shows an organisation in which healthcare personnel continue to make decisions for patients. Significance for nurses to perform a discharge planning that support patients' participation seems to be a communication based on shared understanding.
\end{abstract}

\section{Keywords}

Discharge Planning, Nurses, Older Patients, Rural Area, Qualitative Method 


\section{Introduction}

The in-hospital rehabilitation of patients who have undergone surgery for a hip fracture is a team effort in which nurses play an all-embracing role throughout the patients' hospital stay [1]. In patients' discharge planning (DP), nurses act as coordinators of the process, which begins when patients are admitted and receive initial assessments that inform decisions about whom should be involved [2]. However, nurses face several challenges in their efforts to prepare patients, as well as their families, for discharge back into their homes [3].

Discharge planning can be defined as a process that seeks to coordinate a patient's future care during and beyond hospitalisation. The process involves the collaboration of various members of the healthcare team, including physicians, nurses, physiotherapists, and occupational therapists, as well as patients and their relatives. In cases in which the patient needs help from social services at discharge, a social worker from the municipality also participates [4]. For older people, who often suffer from physical or cognitive disabilities, the DP has been identified as a vulnerable part of hospital stays [5] [6].

Older patients admitted to hospitals generally have concerns about how they will manage at home after discharge. As much as possible, they want to organise the planning in a way that will support their level of independence. Older patients want to be treated with respect, listened to, and involved in decision-making during DP [7]. The degree to which patients, regardless of age, want to be involved in the planning differs [8]. In cases in which DP for older patients have been made by healthcare personnel without the patients' involvement, patients have felt diminished and excluded [9].

After hospital stays, older patients prefer to be discharged to their own homes, which they believe are the best place to recover [10]. Despite the prospect of returning home, it is nevertheless common for the older patient to feel nervous and worried about discharge, especially when they think that they are not ready to leave the hospital [11] [12]. In Sweden, and other European countries older people mostly inhabit rural or sparsely populated areas [13]. Older people often have complex health issues, which can be problematic in such areas due to long distances to healthcare facilities and the lack of public transportation. Research has shown that those trends are also common in for example Australia and the United States [14].

Discharge planning has been studied from numerous perspectives, including those of healthcare personnel [15] [16] [17], patients [7] [18] [19], and relatives [20] [21]. At the same time, research addressing DP has focused on everything from patients' participation in the process [22] [23] [24] to information sharing [25]. To our knowledge little attention has been paid to describing nurses' views on planning discharge for older patients who have undergone hip fracture surgery and live in rural areas.

\section{Aim}

The aim of the study was to describe nurses' views on discharge planning for 
older patients after hip fracture surgery who live in their own homes in rural areas.

\section{Methods}

\subsection{Design}

With a focus on describing nurses' views on DP, a qualitative method was chosen. Qualitative research provide us with detailed and rich knowledge of what is being studied; it gives us an answer to what people think, feel and experience [26]. Data were collected with focus groups interviews (FGI) according to the method of Krueger and Casey [27]. A FGI is a discussion of a small group of individuals on a topic about which all participants have similar background knowledge. Focus groups interviews facilitate interactions among participants, which can afford a variety of perspectives that can enhance the quality of data [27]. The interview texts were analysed with qualitative content analysis per the strategy of Catanzaro [28] that aims at attaining a condensed and broad description of the phenomenon of interest and the outcome of the analysis is presented as categories or themes depending on the level of interpretation [28].

\subsection{Context}

The study was conducted in a region of mid-Sweden at the hospital that supplies healthcare to the entire county, which consists of sparsely populated and rural areas. Every year, approximately 18,000 people in Sweden suffer a hip fracture. In the region investigated, approximately 300 patients undergo surgery for a hip fracture every year [29]. At the orthopaedic clinic within the hospital, a discharge-planning nurse (DPN) coordinates DP for patients. In collaboration with other nurses, the DPN gathers information about patients' capacity to return home. When a patient is ready for discharge and will require help at home, the DPN notifies the DP team from the patient's municipality. If the patient lives in the municipality where the hospital is located, a DP meeting will be held at the hospital otherwise the meeting is held over the telephone. If the patient says she/he will manage at home without municipal help, the discharge planning stays as a collaboration between the patient, their relatives and the hospital healthcare personnel.

\subsection{Participants}

A purposive sample of 18 nurses participated in the study. The criteria for participation were that the nurses had worked at the orthopaedic clinic for at least 6 months and had experience with DP for older patients who had undergone hip fracture surgery. The participants were $24-63(\mathrm{md}=34)$ years old and had worked at the clinic for $1-28(\mathrm{md}=3)$ years. One of the participants had a nurse specialist training. The first author mediated contact with nurses interested in participating. Since nurses were allowed to participate during working hours, the FGIs were planned to accommodate their schedules. 


\subsection{Data Collection}

Data were collected via four FGIs: two with five nurses each and the two others with four nurses each. Conducted during November and December 2016, each FGI was held in a separate room at the nurses' workplace and lasted 63 - 90 (md = 78) min. In each of the four FGIs conducted for the study, the first author acted as the moderator, while one of the two co-authors acted as an observer. The role of the moderator involved guiding the participants through the interview, while that of the observer involved taking notes [27].

To stimulate the discussion, the moderator presented a vignette [30] at the beginning of each interview. The vignette described the fictional case of an older woman who lived alone in a rural area and was admitted with a hip fracture to an orthopaedic clinic. Participants were asked to tell how they would plan the patient's discharge. Following the description of the vignette, the moderator referred to an interview guide with open-ended questions and prompts (e.g. "Tell me about patient participation in discharge planning") with follow-up questions such as "Can you tell me more about that?", "What do you mean?", and "Can you give an example?". At the end of each FGI, the moderator summarised the discussion in order to ensure that it was accurately perceived. After each FGI, the observer discussed the notes with the moderator. The FGIs were digitally recorded and transcribed verbatim by the first author.

\subsection{Data Analysis}

The interviews texts were analysed with qualitative content analysis per the strategy of Catanzaro [28]. At first, the interviews texts were read several times in order to get an overall picture of the content. The text was then divided into meaning units related to the aim of the study. A meaning unit is the smallest unit that contains some understanding that the investigators needs and may be as small as a sentence or as large as a paragraph. The meanings units were condensed, coded and sorted into four categories based on similarities and differences in content. The four categories were then subsumed into one theme [28]. All authors were involved in the analysis and the interpretations were discussed until consensus was obtained.

\subsection{Ethical Considerations}

Participating nurses provided their informed consent to participate. At a nurse meeting, the nurses received written and oral information about the study from the first author, including information about their right to withdraw from the study at any time for any or no reason. At the beginning of the FGI, the same information was repeated. The participants were guaranteed confidentiality and an anonymous presentation of the findings. The study was approved by the Regional Ethical Review Board in Umeå, Sweden (DNR No. 2016-154-31), and by the head of the orthopaedic clinic at the hospital. 


\section{Findings}

The analysis resulted in one theme, "A spider in a broken web" constructed from four categories: being supportive, involving relatives, not always focusing on patients' needs, and difficulties to influence. The categories are presented in the text below and illustrated with quotations from the FGIs to verify the data analysis.

\subsection{Being Supportive}

Nurses expressed seeking to prepare the patients as much as possible in order for them to feel safe upon discharge from the hospital. That process involved understanding what the patients wanted, providing information, and strengthening their sense of independence. Nurses described the typical patient with a hip fracture as an older person who was used to taking care of him or herself. Suffering from a hip fracture usually required the patient to need help at discharge due to physical impairment. For that reason, older patients typically found it difficult to accept their new situations, which included the risk of never returning home or at least having to accept that their homes would need adjustments to accommodate physical impairments. Such adjustments included having to rely on others to manage activities of daily life. Nurses described notifying patients early during the hospital stay that they might need help at home upon discharge in order to give the patients time to get used to the idea.

You ask the patient what he or she wants and thinks that he or she needs in order to succeed at home and whether she wants the municipality to be involved in the discharge planning (FGI 2).

Nurses expressed that since a well-informed patient managed better at home, it was important to provide information throughout the hospital stay. The information necessarily differed from patient to patient and could relate to getting help from the municipality at home, taking medication, and knowing whom to contact if they had any questions once they returned home. Stressing patients' difficulty with remembering what information had been discussed, nurses described wanting to provide more information in writing, which would allow patients to stay informed at home.

Sometimes I think that the more I inform the patient, the more confused he/she gets. It would be better if they got it [information] in writing to read at home (FGI 4).

Nurses also reported aiming to strengthen patients' sense of independence, encouraging them to manage activities of daily life themselves as much as possible, and, while doing so, telling the patients that they were handling the situation well. At the same time, they expressed needing to stay realistic and to not give patients false expectations. Nurses admitted that it was sometimes difficult to let patients manage on their own due to lack of time, which in some cases made patients passive and unwilling to attempt tasks on their own. When nurses en- 
couraged patients to manage tasks by themselves, their presence was sometimes questioned: "One patient said to me, if you aren't going to help me, then what are you doing here?" (FGI 2). When encouraging patients to manage their recovery on their own, nurses reported how some patients realised that they would need help after being discharged from the hospital even if they were initially reluctant to accept that reality.

\subsection{Involving Relatives}

Nurses expressed that relatives of patients were important to patients during DP and they described having regular contact with relatives during the hospital stay, providing that the patient agreed. Nurses reported that relatives were helpful in many ways and often offered to help more than they could be expected to: "I mean, they have their lives". You can't just expect them to put everything on hold to come and help their moms" (FGI 3).

Nurses said that relatives were also a source of information about the patients' situation at home, especially when patients claimed that they could manage their recovery with the help of their grown-up children or spouses. They described that when patients and relatives differed in opinions regarding the patients' capacity to recover at home, family relations could become complicated. In one such case, a patient claimed to be able to manage recovery without help from the municipality because the spouse at home could provide assistance. When asked, the spouse reported no longer being able to care for two people but had struggled to admit that reality to the patient. Nurses, uncertain of families' situations at home, described trying their best to mediate between patients and their relatives but ultimately feeling that their role involved supporting the patients. They reported that not all relatives of patients were easy to accommodate. Some relatives were perceived as being unreasonably demanding, uninterested in helping themselves, or disappointed with the care provided. Others assumed control of discharge planning and claimed to know what was best for the patients. Nurses said that they worried for patients who did not have any relatives at all.

\subsection{Not Always Focusing on Patients' Needs}

Nurses described patients' vulnerability to not having their needs met and, at times, their inability to influence the outcome of DP outside the hospital. They expressed concern that DP meetings with municipal staff were mere formalities and that plans were already established due to structural and organisational conditions. Fearing that the uniqueness of each patient was lost in order to make the patient fit into the system instead of meeting his or her needs, nurses expressed the need for a more flexible DP. They discussed how patients who needed care from the municipality after discharge had few options to receive such care-among them, receiving home care or care at a short-term nursing home. Although the patient's condition was supposed to determine the outcome, nurses reported how increasingly more patients were sent home despite their 
extensive care needs and felt insecure due to the lack of short-term nursing homes.

It hurts all the way to my soul to know that an old woman isn't going to get help that she wants. Instead, decisions are made by the social worker from the municipality (FGI 3).

Nurses described that when a DP meeting occurred at the hospital, the number of attendees inhibited the patient's ability to communicate his or her wishes. Consequently, the patient simply agreed to what the team from the municipality proposed. Nurses reported that after those meetings, patients would ask them why they had to participate when the team from the municipality did not seem to listen to their opinions. Nurses speculated how having a social worker from the hospital at the meetings to advocate for patients would benefit anxious patients, ones whose relatives could not attend, and the ones who had no relatives.

Nurses described that patients' inability to influence DP became obvious when patients ready to leave could influence neither the day nor time of discharge. Discharge notices often arrived only a day in advance, which often increased patients' anxiety. By contrast, when unforeseen events postponed discharge, nurses described that patients seemed to become more relaxed and more confident with the idea of returning home.

\subsection{Difficulties to Influence}

Nurses enumerated several circumstances-lack of hospital resources, deficient collaboration among healthcare personnel, and blind acceptance of patients' decisions-that they could not influence regarding DP and that prompted feelings of frustration. They described that although the healthcare team generally collaborated, a change both within and outside their own organisation had occurred in recent years. They described an unwillingness to help each other between the organisations involved in DP, which negatively affected collaboration. Nurses described worrying about how patients would manage at home especially when patients had declined help from the municipality. In such cases, nurses reported repeatedly encouraging patients to reconsider, yet ultimately being unable to do anything but accept the patients' decision, even if they harboured intuitive doubts.

I can speak only about the situations that I've been involved in, and in those cases, I believe that I've done everything that I can to try to convince the patient to get help at home. If I don't succeed, there isn't much that I can do (FGI 2).

Nurses described that despite wanting to know what happens to patients after discharge, they received feedback only when municipal personnel were unsatisfied with the care provided or the patient was re-admitted. In cases in which they had truly worried about sending a patient home, nurses took the initiative to follow-up informally, which assuaged their worries and earned the patient's appreciation for the effort. However, nurses admitted that they could not routinely 
conduct informal follow-ups due to lack of time and resources, and they questioned what they would do upon learning that a patient's recovery at home had gone awry.

You assume that you've done everything right. I mean, you have to do that.

But since we don't get any feedback, we don't know how the patient is managing at home (FGI 1).

\section{Discussion}

The aim of the study was to describe nurses' views on DP for older patients after hip fracture surgery into their own homes in rural areas. The findings show that nurses believed that patients need support from healthcare personnel as well as relatives in order to prepare for life at home. They expressed that patients were not supported in all aspects of DP due to patients' difficulties in having their voices heard. Patients' participation is multi-dimensional and involves mutual, individualised communication in which nurses conceive patients as a resource and listen to what they have to say [31]. Consequently, communication is an essential facilitator of patients' participation in DP. Without communication based on a shared understanding and a nurse-patient dialogue, patients' opportunities for participating and influencing DP will be limited.

Nurses described that many aspects surrounding DP were beyond their control, which left them with little ability to influence DP. Further, findings show that nurses considered DP to require a team-based effort in which they were responsible for coordinating the planning. That responsibility involved trying to protect patients' autonomy while balancing organisational barriers such as lack of communication and of trust between the healthcare organisation and the municipality. The theme "a spider in a broken web" illustrates the challenges nurses in this study face while not being able to control every aspect of DP although playing a central part.

The study's findings show that supporting and strengthening patients' sense of independence is an important part of DP. Nurses expressed that well-informed patients manage their daily lives at home better. According to Irurita [32], patients who are informed and have knowledge about what to expect during their care are less vulnerable than ones who are lacking influence over their care. It was problematic for the nurses in this study to let patients perform activities of daily life by themselves because they lacked the time to offer assistance. At the same time, nurses described wanting to encourage the patients' sense of independence after their discharge. Chan et al. [33] have shown that when nurses follow routines in their work, patients' individual needs are overlooked. In the same vein, nurses reported that though having conversations with patients is pivotal to good care, it was difficult to manage such conversations due to lack of time. Gesar et al. [34] found that patients became passive during their hospital stays due to stress with adapting to routines instead of progressing at their own pace. To avoid such passivity, nurses need to be sensitive to each patient's needs 
and depart from routines as necessary.

The nurses described the importance of patients' relatives in the success in $\mathrm{DP}$, as well as that relatives were often willing to help more than could be expected of them. That finding aligns with the results of Rustad et al. [35] and Bragstad et al. [36], who found that older patients' relatives consider it their duty to help the patients even if it takes significant time and effort. However, if what relatives believes is best for the patient differs from the opinion of healthcare personnel, then they can be perceived as obstacles by healthcare staff and left uninvolved [37].

The findings also reveal that the nurses thought that DP meetings with personnel from the municipality did not always consider patients' needs, largely because patients felt that they were not encouraged to voice their opinions. According to Efraimsson et al. [38], older patients have difficulties participating in DP meetings because they are not accustomed to the form of the meeting or the vocabulary used. A particular disadvantage for patients who have recently undergone hip fracture surgery may be that they are in pain or feel unwell [39]. Studies [39] [40] have shown that older patients do not feel sufficiently competent to participate in determining their care. That trend underscores the importance of facilitating DP that respects patients' preferences, remains sensitive to and supportive of patients, and gives patients who want to participate in planning the opportunity to do so.

The nurses in the study suggested that having the social worker from the hospital attend DP meetings could improve patients' ability to influence the outcomes of DP. This finding is unexpected since advocating is part of nursing care [41]. Vaartio et al. [42] have shown that nursing advocacy involves clarifying patients' expectations, responding to expressions and needs, protect patients from harm, and drawing attention to patients' rights and needs. The nurses in this study seemed to struggle to protect patients' rights during their contact with the team from the municipality. Possible explanations are that the team from the municipality was from another organisation and that nurses role at the meeting are unclear. Water et al. [43] described that nurses sometimes are expected to advocate for their patients in institutional cultures in which they lack authority and have limited power.

The findings moreover show that nurses found it difficult to accept patients' decisions to decline help from the municipality. Achieving dialogue between patients and healthcare personnel is important to creating shared understanding [44]. In times when opinions differ, the challenge is to respect and listen to other parties. Perhaps the nurses in the study remained wary of patients' resistance to help in light of past cases in which patients had been readmitted. Durocher et al. [45] have shown that healthcare personnel struggle to find a balance between respecting patients' autonomy and ensuring safe discharges.

The rural setting addressed in the study did not seem to affect DP and the findings are in line with other studies [3] [16] [17] in different contexts. Nurses rarely discussed the effects of the rural setting, although mentioning problems of 
old houses with several floors and long distances to the hospital. However, it could be that the nurses, in perceiving the discharge of patients to their homes in a rural area as part of their everyday lives, do not think that the setting makes a difference.

\section{Methodological Discussion}

To promote trustworthiness in this study several steps have been taken, for instance, the setting, participants and procedure has been clearly described [46]. Further, the sample size in this study has been guided by Malterud et al. [47]. According to Malterud et al. [47] information power is a concept that can be used as guide for sample size and means that the more information the sample holds, the fewer participants are required. Follow this sample suitability and data quality is more important than the number of participants. Based on this we considered the sample size in this study to be large enough because it contributed richness and depth to the analysis.

Focus groups interviews, poses the disadvantage that some participants can dominate the discussion and thereby inhibit other participants from speaking [27]. In anticipation of that possibility, the moderator of the FGIs ensured that every participant had the opportunity to speak. From another angle, each FGI involved only four and five participants, which is slightly smaller than the recommended group size [27]. However, smaller groups can also maximise discussion and facilitate order [48]. Moreover, at the end of each FGI, the moderator summarised the discussion in front of the participants to ensure that they had accurately perceived the discussion.

\section{Conclusion}

This study contributes knowledge of nurses' views on DP for patients who have undergone hip fracture surgery and who are discharged into their own homes in rural areas. Discharge planning is supposed to meet each unique patient's wishes and needs within the confines of available resources. The organisation presented in the study is one in which healthcare personnel continue to make decisions for patients. A key factor for nurses to perform a DP that support patients' participation seems to be a communication based on shared understanding. This study showed that the rural context did not seem to affect DP from nurses' perspectives, and since patients played a key part in DP, further research should explore the perspective of older patients as well as nurses in DP in rural context.

\section{Acknowledgements}

The authors would like to thank the participating nurses that shared their views with us.

\section{Declaration}

This study was approved by the Regional Ethical Review Board in Umeå, Sweden 
(DNR No. 2016-154-31). The authors declare no conflict of interest.

\section{References}

[1] Olsson, L., Karlsson, J. and Ekman, I. (2007) Effects of Nursing Interventions within an Integrated Care Pathway for Patients with Hip Fracture. Journal of Advanced Nursing, 58, 116-125. https://doi.org/10.1111/j.1365-2648.2007.04209.x

[2] Rhudy, L.M., Holland, D.E. and Bowles, K.H. (2010) Illuminating Hospital Discharge Planning: Staff Nurse Decision Making. Applied Nursing Research, 23, 198-206.

[3] Nosbusch, J.M., Weiss, M.E. and Bobay, K.L. (2011) An Integrated Review of the Literature on Challenges Confronting the Acute Care Staff Nurse in Discharge Planning. Journal of Clinical Nursing, 20, 754-774. https://doi.org/10.1111/j.1365-2702.2010.03257.x

[4] National Board of Health and Welfare (2005) SOSFS 2005:27 Socialstyrelsens föreskrifter om samverkan vid in-och utskrivning av patienter i sluten vård [Instructions for Collaboration at Admission and Discharge of Patients in Hospitals]. Stockholm.

[5] Coffey, A. (2006) Discharging Older People from Hospital to Home: What Do We Know? International Journal of Older People Nursing, 1, 141-150. https://doi.org/10.1111/j.1748-3743.2006.00023.x

[6] Foust, J.B. (2007) Discharge Planning as Part of Daily Nursing Practice. Applied Nursing Research, 20, 72-77.

[7] Gabrielsson-Järhult, F. and Nilsen, P. (2016) On the Threshold: Older People's Concerns about Needs after Discharge from Hospital. Scandinavian Journal of Caring Sciences, 30, 135-144. https://doi.org/10.1111/scs.12231

[8] Ekdahl, A.W., Andersson, L. and Friedrichsen, M. (2010) “They Do What They Think Is the Best for Me”. Frail Elderly Patients' Preferences for Participation in Their Care during Hospitalization. Patient Education and Counseling, 80, 233-240. https://doi.org/10.1016/j.pec.2009.10.026

[9] Rydeman, I., Törnkvist, L., Agreus, L. and Dahlberg, K. (2012) Being In-Between and Lost in the Discharge Process-An Excursus of Two Empirical Studies of Older Persons', Their Relatives', and Care Professionals' Experience. International Journal of Qualitative Studies on Health and Well-being, 7, 1-9.

[10] Randström, K.B., Asplund, K., Svedlund, M. and Paulson, M. (2013) Activity and Participation in Home Rehabilitation: Older People's and Family Members' Perspectives. Journal of Rehabilitation Medicine, 45, 211-216. https://doi.org/10.2340/16501977-1085

[11] Forsberg, A., Soderberg, S. and Engstrom, A. (2014) People's Experiences of Suffering a Lower Limb Fracture and Undergoing Surgery. Journal of Clinical Nursing, 23, 191-200. https://doi.org/10.1111/jocn.12292

[12] Toscan, J., Manderson, B., Santi, S. and Stolee, P. (2013) "Just Another Fish in the Pond": The Transitional Care Experience of a Hip Fracture Patient. International Journal of Integrated Care, 13, e023. https://doi.org/10.5334/ijic.1103

[13] Burholt, V. and Dobbs, C. (2012) Research on Rural Ageing: Where Have We Got to and Where Are We Going in Europe? Journal of Rural Studies, 28, 432-446. https://doi.org/10.1016/j.jrurstud.2012.01.009

[14] Scharf, T., Walsh, K. and O’Shea, E. (2016) Ageing in Rural Places. In: Shucksmith, M. and Brown, D.L., Eds., Routledge International Handbook of Rural Studies, 
Routledge, New York, 86-100.

[15] Rydeman, I. and Törnkvist, L. (2006) The Patient's Vulnerability, Dependence and Exposed Situation in the Discharge Process: Experiences of District Nurses, Geriatric Nurses and Social Workers. Journal of Clinical Nursing, 15, 1299-1307. https://doi.org/10.1111/j.1365-2702.2006.01379.x

[16] Connolly, M., Grimshaw, J., Dodd, M., Cawthorne, J., Hulme, T., Everitt, S., Tierny, S. and Deaton, C. (2009) Systems and People under Pressure: The Discharge Process in an Acute Hospital. Journal of Clinical Nursing, 18, 549-558. https://doi.org/10.1111/j.1365-2702.2008.02551.x

[17] Watts, R. and Gardner, H. (2005) Nurses' Perceptions of Discharge Planning. Nursing \& Health Sciences, 7, 175-183. https://doi.org/10.1111/j.1442-2018.2005.00229.x

[18] Coffey, A. and McCarthy, G.M. (2013) Older People's Perception of Their Readiness for Discharge and Postdischarge Use of Community Support and Services. International Journal of Older People Nursing, 8, 104-115. https://doi.org/10.1111/j.1748-3743.2012.00316.x

[19] Grimmer, K., Moss, J. and Falco, J. (2004) Experiences of Elderly Patients Regarding Independent Community Living after Discharge from Hospital: A Longitudinal Study. International Journal for Quality in Health Care, 16, 465-472. https://doi.org/10.1093/intqhc/mzh071

[20] Denson, L.A., Winefield, H.R. and Beilby, J.J. (2013) Discharge-Planning for Long-Term Care Needs: The Values and Priorities of Older People, Their Younger Relatives and Health Professionals. Scandinavian Journal of Caring Sciences, 27, 3-12. https://doi.org/10.1111/j.1471-6712.2012.00987.x

[21] Rydeman, I. and Törnkvist, L. (2010) Getting Prepared for Life at Home in the Discharge Process-From the Perspective of the Older Persons and Their Relatives. International Journal of Older People Nursing, 5, 54-264. https://doi.org/10.1111/j.1748-3743.2009.00190.x

[22] Efraimsson, E., Sandman, P.O. and Rasmussen, B.H. (2006) "They Were Talking about Me"-Elderly Women's Experiences of Taking Part in a Discharge Planning Conference. Scandinavian Journal of Caring Sciences, 20, 68-78. https://doi.org/10.1111/j.1471-6712.2006.00382.x

[23] Foss, C. and Askautrud, M. (2010) Measuring the Participation of Elderly Patients in the Discharge Process from Hospital: A Critical Review of Existing Instruments. Scandinavian Journal of Caring Sciences, 24, 46-55. https://doi.org/10.1111/j.1471-6712.2010.00788.x

[24] Foss, C. and Hofoss, D. (2011) Elderly Persons' Experiences of Participation in Hospital Discharge Process. Patient Education and Counseling, 85, 68-73. https://doi.org/10.1016/j.pec.2010.08.025

[25] Nordmark, S., Söderberg, S. and Skär, L. (2015) Information Exchange between Registered Nurses and District Nurses during the Discharge Planning Process: Cross-Sectional Analysis of Survey Data. Informatics for Health and Social Care, 40, 23-44. https://doi.org/10.3109/17538157.2013.872110

[26] Patton, M.Q. (2015) Qualitative Research \& Evaluation Methods: Integrating Theory and Practice. 4th Edition, SAGE Publications, Thousand Oaks.

[27] Krueger, R.A. and Casey, M.A. (2014) Focus Groups: A Practical Guide for Applied Research. SAGE Publications, Thousand Oaks.

[28] Catanzaro, M. (1988) Using Qualitative Analytical Techniques. In: Woods, N. and Catanzaro, M., Eds., Nursing Research: Theory and Practice, Mosby Incorporated, St Louis, 437-456. 
[29] Rikshöft (2016) Årsrapport (Annual Report in Swedish). http://rikshoft.se/wp-content/uploads/2013/07/Årsrapport_2015.pdf

[30] Hughes, R. and Huby, M. (2002) The Application of Vignettes in Social and Nursing Research. Journal of Advanced Nursing, 37, 382-386. https://doi.org/10.1046/j.1365-2648.2002.02100.x

[31] Eldh, A.C., Luhr, K. and Ehnfors, M. (2015) The Development and Initial Validation of a Clinical Tool for Patients' Preferences on Patient Participation-The 4Ps. Health Expectations, 18, 2522-2535. https://doi.org/10.1111/hex.12221

[32] Irurita, V. (1999) Factors Affecting the Quality of Nursing Care: The Patient's Perspective. International Journal of Nursing Practice, 5, 86-94. https://doi.org/10.1046/j.1440-172x.1999.00156.x

[33] Chan, E.A., Jones, A. and Wong, K. (2013) The Relationships between Communication, Care and Time Are Intertwined: A Narrative Inquiry Exploring the Impact of Time on Registered Nurses Work. Journal of Advanced Nursing, 69, 2020-2029. https://doi.org/10.1111/jan.12064

[34] Gesar, B., Hommel, A., Hedin, H. and Bååth, C. (2017) Older Patients' Perception of Their Own Capacity to Regain Pre-Fracture Function after Hip Fracture Surgery-An Explorative Qualitative Study. International Journal of Orthopaedic and Trauma Nursing, 24, 50-58. https://doi.org/10.1016/j.ijotn.2016.04.005

[35] Rustad, E.C., Seiger Cronfalk, B., Furnes, B. and Dysvik, E. (2017) Next of Kin’s Experiences of Information and Responsibility during Their Older Relatives' Care Transitions from Hospital to Municipal Health Care. Journal of Clinical Nursing, 26, 964-974. https://doi.org/10.1111/jocn.13511

[36] Bragstad, L.K., Kirkevold, M. and Foss, C. (2014) The Indispensable Intermediaries: A Qualitative Study of Informal Caregivers' Struggle to Achieve Influence at and after Hospital Discharge. BMC Health Services Research, 14, 315-326.

https://doi.org/10.1186/1472-6963-14-331

[37] Bøttcher Berthelsen, C., Lindhardt, T. and Frederiksen, K. (2014) Inhibiting Interference-A Grounded Theory of Health Professionals' Pattern of Behaviour Related to the Relatives of Older Patients in Fast-Track Treatment Programmes. Scandinavian Journal of Caring Sciences, 28, 609-617. https://doi.org/10.1111/scs.12126

[38] Efraimsson, E., Sandman, P.O., Hydén, L.C. and Rasmussen, B.H. (2004) Discharge Planning: "Fooling Ourselves?"-Patient Participation in Conferences. Journal of Clinical Nursing, 13, 562-570. https://doi.org/10.1111/j.1365-2702.2004.00900.x

[39] Tobiano, G., Bucknall, T., Marshall, A., Guinane, J. and Chaboyer, W. (2016) Patients' Perceptions of Participation in Nursing Care on Medical Wards. Scandinavian Journal of Caring Sciences, 30, 260-270. https://doi.org/10.1111/scs.12237

[40] Huby, G., Brook, J.H., Thompson, A. and Tierny, A. (2007) Capturing the Concealed: Interprofessional Practice and Older Patients' Participation in Decision-Making about Discharge after Acute Hospitalization. Journal of Interprofessional Care, 21, 55-67. https://doi.org/10.1080/13561820601035020

[41] Zomorodi, M. and Foley, B.J. (2009) The Nature of Advocacy vs. Paternalism in Nursing: Clarifying the "Thin Line". Journal of Advanced Nursing, 65, 1746-1752. https://doi.org/10.1111/j.1365-2648.2009.05023.x

[42] Vaartio, H., Leino-Kilpi, H., Salanterä, S. and Suominen, T. (2006) Nursing Advocacy: How Is It Defined by Patients and Nurses, What Does It Involve and How Is It Experienced? Scandinavian Journal of Caring Sciences, 20, 282-292.

https://doi.org/10.1111/j.1471-6712.2006.00406.x 
[43] Water, T., Ford, K., Spence, D. and Rasmussen, S. (2016) Patient Advocacy by Nurses-Past, Present and Future. Contemporary Nurse, 52, 696-709. https://doi.org/10.1080/10376178.2016.1235981

[44] Tveiten, S. and Knutsen, I.R. (2011) Empowering Dialogues-The Patients' Perspective. Scandinavian Journal of Caring Sciences, 25, 333-340. https://doi.org/10.1111/j.1471-6712.2010.00831.x

[45] Durocher, E., Kinsella, E.A., Ells, C. and Hunt, M. (2015) Contradictions in Client-Centred Discharge Planning: Through the Lens of Relational Autonomy. Scandinavian Journal of Occupational Therapy, 22, 293-301. https://doi.org/10.3109/11038128.2015.1017531

[46] Lincoln, Y.S. and Guba, E.G. (1985) Naturalistic Inquiry. SAGE Publications, Newbury Park.

[47] Malterud, K., Siersma, V.D. and Guassora, A.D. (2016) Sample Size in Qualitative Interview Studies: Guided by Information Power. Qualitative Health Research, 26, 1753-1760. https://doi.org/10.1177/1049732315617444

[48] Peek, L. and Fothergill, A. (2009) Using Focus Groups: Lessons from Studying Daycare Centers, 9/11, and Hurricane Katrina. Qualitative Research, 9, 31-59.

https://doi.org/10.1177/1468794108098029 